\title{
PHILOSOPHY OF MIND AND COGNITIVE MODELLING IN EDUCATION
}

\author{
Boris Aberšek \\ University of Maribor, Slovenia \\ E-mail: boris.abersek@uni-mb.si
}

One of the main reasons there is so much junk in education is that there are so few people who know enough about education and about the sciences that support education, i.e. philosophy, cognitive and neuroscience to put the thing together. Educators have been reliant upon others' expertise for the interpretations from contemporary science hence have not been able to discern whether the claims made are valid or invalid representations of the research. Without a direct access to the primary research educators may be at risk of misusing results from this advanced research. The need for so called 'mediator' in the translation of research to practice has led to a situation where the application of cognitive neuroscience research findings is running ahead of the research itself.

In order to negate the need for mediator, some researchers have suggested the need to develop a group of "neuro-educators", specially trained teams of professionals whose role would be to guide the introduction of philosophy of mind, cognitive and neuroscience into educational practice in a "sensible and ethical manner". Mediators, so called neuro-educators would play a pivotal role in assessing the quality of evidence purporting to be relevant to education, assessing who is best placed to employ newly developed knowledge, and with what safeguards, and how to deal with unexpected consequences of implemented research findings.

Generally the educators fall into one of four orientations with respect to neuroscientific research:

- Those who readily accept (and sometimes over interpret) the results of neuroscientific studies;

- Those who completely reject the neuroscientific approach and consider the results of neuroscientific studies to be meaningless;

- Those who are unfamiliar with and indifferent toward, neuroscientific research; and

- Those who cautiously accept neuroscientific findings as being a proactive part of the total pattern of findings that have emerged from different corners of the cognitive and neural sciences".

Leading researchers suggest that as the body of knowledge available to educator's increases, and the ability to be expert in all areas diminishes, the most productive standpoint would the fourth outlined by that of cautious acceptance of neuroscientific findings and proactive collaboration. They also point out that "teachers must be aware of and act on the science within the art of teaching". They suggest that educators must become aware of other methods and incorporate them into their practice. Furthermore, they suggest that specific bodies of knowledge will play an important role in informing educators when making important decisions with regards to the "design of learning environments". The bodies of knowledge discussed include multiple intelligences, learning styles, human brain and last but not list the socio cultural and anthropological phenomena of the students. As the authors explain these and other areas are just "lenses designed to extend teachers' understanding of how students learn, 
PROBLEMS

OF EDUCATION

IN THE $21^{\text {st }}$ CENTURY

Volume 46, 2012

and from that understanding, to make decisions about how and when to select, integrate, and enact items in the educational process.

Many researchers support calls for a two-way constructive collaboration between science (philosophy, cognitive and neuroscience) and education, whereby, rather than science research simply being applied to education, findings from science research would be used to constrain educational theorizing. In return, education would influence the types of research questions and experimental paradigms used in science research. We can conclude, that while pedagogical practice in the classroom may give rise to educational questions regarding the emotional basis of performance on school tasks, science (philosophy, cognitive and neuroscience) has the potential to reveal the brain basis of higher-order thinking processes and thus may help to understand the role that emotion plays in learning and open new areas of study of emotional thought in the classroom.

The papers presented in this volume also try to connect science and research with education and application of science in everyday practice. At the University of Maribor, Faculty of natural science and mathematics with support of the experts in the field of Philosophy of Mind, Cognitive Science, Psychology, Neuroscience, Artificial Intelligence and Education try to establish a group of "neuro-educators". The aim of this group will be to promote further international co-operation among Scientists from different disciplines involved in the study of Philosophy of Mind and Cognitive Modelling in Education. The overall objective is to produce an integrated approach to problems of connection Education with the contemporary knowledge from the area of Philosophy of Mind, Cognitive Science, Psychology, Neuroscience, Cognitive modelling and Artificial Intelligence. Presented papers are first attempt to reach such aims. 